\begin{tabular}{|c|c|c|}
\hline \multirow{3}{*}{$\begin{array}{r}\text { Case Reports in } \\
\text { Gastroenterology }\end{array}$} & \multicolumn{2}{|c|}{ Case Rep Gastroenterol 2013;7:69-74 } \\
\hline & $\begin{array}{l}\text { DOI: 10.1159/000348754 } \\
\text { Published online: March 1, } 2013\end{array}$ & $\begin{array}{l}\text { (c) } 2013 \text { S. Karger AG, Basel } \\
1662-0631 / 13 / 0071-0069 \$ 38.00 / 0 \\
\text { www.karger.com/crg }\end{array}$ \\
\hline & $\begin{array}{l}\text { This is an Open Access article licen } \\
\text { NonCommercial-NoDerivs } 3.0 \mathrm{Li} \\
\text { online version of the article only. }\end{array}$ & $\begin{array}{l}\text { Is of the Creative Commons Attribution } \\
\text { er.com/OA-license), applicable to the } \\
\text { on-commercial purposes only. }\end{array}$ \\
\hline
\end{tabular}

\title{
Synchronous Sporadic Gastrointestinal Stromal Tumors in the Stomach and Jejunum: Report of a Case
}

\author{
Yoshifumi Nakayama ${ }^{a, c}$ Kouji Kadowaki ${ }^{a} \quad$ Aiichirou Higure $^{a}$ \\ Masanori Hisaokab Koji Yamaguchi ${ }^{\mathrm{a}}$ \\ Departments of a Surgery 1 and ${ }^{b}$ Pathology and Oncology, School of Medicine, University \\ of Occupational and Environmental Health, and ${ }^{\mathrm{C} D e p a r t m e n t}$ of Gastroenterological and \\ General Surgery, Wakamatsu Hospital of University of Occupational and Environmental \\ Health, Kitakyushu, Japan
}

\section{Key Words}

Gastrointestinal stromal tumor · Sporadic · Synchronous · Stomach · Jejunum

\begin{abstract}
This report describes a patient with synchronous sporadic gastrointestinal stromal tumors (GISTs) in the stomach and jejunum. A 71-year-old Japanese male presented with a 2-year history of occasional melena and general fatigue. Computed tomography of the abdomen demonstrated an enhanced extramural gastric tumor, $4 \mathrm{~cm}$ in diameter. Endoscopic examination revealed a jejunal submucosal tumor. He was referred to the surgical outpatient clinic for surgical treatment of an extramural gastric tumor and a jejunal submucosal tumor. Laparotomy allowed the identification of a nut-sized extramural tumor at the stomach and a thumb's head-sized tumor on the jejunum. Partial resections of the stomach and jejunum were performed. Histopathological and immunohistochemical examination revealed that these tumors were GISTs. Although no molecular analysis was performed, the immunohistochemical staining patterns of these two tumors were different from each other. Therefore, the final diagnosis was synchronous sporadic GISTs in the stomach and jejunum. This patient has survived without recurrence for approximately 12 years since complete resection.
\end{abstract}

Yoshifumi Nakayama

Department of Surgery 1, School of Medicine

University of Occupational and Environmental Health

1-1 Iseigaoka, Yahata-nishi-ku, Kitakyushu 807-8555 (Japan)

E-Mail nakayama@med.uoeh-u.ac.jp 


\begin{tabular}{l|l}
\hline DOI: $10.1159 / 000348754$ & $\begin{array}{l}\odot 2013 \text { S. Karger AG, Basel } \\
\text { www.karger.com/crg }\end{array}$ \\
\hline \multicolumn{2}{l}{ Nakayama et al.: Synchronous Sporadic Gastrointestinal Stromal Tumors in the Stomach }
\end{tabular}
and Jejunum: Report of a Case

\section{Introduction}

Gastrointestinal stromal tumors (GISTs) are the most common mesenchymal tumors of the gastrointestinal tract. GISTs originate from the interstitial cells of Cajal (ICC) or their stem cell-like precursors [1, 2]. Most GISTs express a receptor tyrosine kinase, KIT [1]. KIT is encoded by the c-KIT gene and its ligand is stem cell factor (SCF). GISTs frequently have a mutation of the c-KIT gene which results in constitutive activation of KIT without stimulation by SCF [1]. GISTs usually show positive immunohistochemical reactivity with CD117 (c-kit) antibody [3].

The incidence of GISTs is estimated as 10-20/million [3]. The median ages in the largest series of GISTs of different locations have ranged between 55 and 65 years [3]. There is equal gender distribution in the patients with GISTs [3]. The malignant potential of GISTs varies from virtually benign to aggressive tumors. Of all GISTs, $20-30 \%$ are malignant tumors [3]. The stomach and small intestine are the most commonly affected anatomic sites, accounting for about two thirds and one third of cases, respectively [2].

GIST is considered to be a solitary tumor and the occurrence of multiple primary lesions is very rare, restricted to familial GISTs [4], pediatric forms [5], or district syndromes such as type 1 neurofibromatosis (NF1) or von Recklinghausen disease [6] or Carney's syndrome [7]. All these are well-defined entities that can be easily distinguished from common sporadic GISTs based on their peculiar clinicopathological features. Multiple sporadic GISTs in different organs are rare [8-10]. This report presents a surgical case of sporadic synchronous GISTs in the stomach and jejunum.

\section{Case Report}

A 71-year-old Japanese male presented with a 2-year history of occasional melena and general fatigue. Computed tomography of the abdomen demonstrated an enhanced extramural tumor of the stomach, $4 \mathrm{~cm}$ in diameter (fig. 1a), but did not indicate a jejunal tumor. Endoscopic examination revealed a jejunal submucosal tumor (fig. 1b), but could not identify the gastric lesion. An upper gastrointestinal series revealed a submucosal jejunal tumor near the Treitz ligament, $2.5 \mathrm{~cm}$ in diameter (data not shown). The patient was referred to the surgical outpatient clinic for surgical treatment of an extramural tumor of the stomach and a submucosal tumor of the jejunum.

Physical examination revealed no conjunctival pallor, and there was no muscular rigidity or rebound tenderness in response to abdominal palpation. Laboratory investigations revealed a white blood cell count of $3,200 / \mathrm{mm}^{3}$, a hemoglobin of $8.3 \mathrm{~g} / \mathrm{dl}$ with a hematocrit of $25.8 \%, 321,000 / \mathrm{mm}^{3}$ platelets, normal electrolytes, as well as normal blood urea nitrogen levels and normal liver function. CEA was $<1.0 \mathrm{ng} / \mathrm{ml}$ and CA19-9 was $6.0 \mathrm{U} / \mathrm{ml}$.

Laparotomy revealed a nut-sized extramural tumor at the lesser curvature of the middle stomach (fig. 2a) that was white-yellow, elastic soft and had dilated vessels on the surface. This gastric tumor was $4 \times 3.5 \times 2.5 \mathrm{~cm}$. A thumb's head-sized tumor was also identified on the jejunum about $15 \mathrm{~cm}$ from the anal side of the Treitz ligament (fig. 2b). This jejunal tumor had transmural growth and was $4 \times 2.5 \times 2 \mathrm{~cm}$. Therefore, partial resections of the stomach and jejunum were performed.

Histopathological examination with hematoxylin and eosin staining revealed that the gastric tumor was composed of a proliferation of spindle cells with spindle nuclei and eosinophilic fibrillar cytoplasm, arranged in fascicles with a hypercellular area (fig. 3a), and the jejunal tumor contained a proliferation of spindle cells with oval or spindle nuclei and 
Nakayama et al.: Synchronous Sporadic Gastrointestinal Stromal Tumors in the Stomach and Jejunum: Report of a Case

occasional pleomorphic cells, arranged in a fascicular or haphazard fashion, alternating with areas of epithelioid features (fig. 3b). The immunohistochemical staining patterns of two these tumors were different. The gastric tumor was positive for c-kit (fig. 3c), CD34 (fig. 3e) and neuron-specific enolase (NSE) (fig. 3i), but negative for smooth muscle actin (SMA) (fig. 3g). On the other hand, the jejunal tumor was positive of c-kit (fig. 3d), SMA (fig. 3h) and NSE (fig. 3j), but negative for CD34 (fig. 3f). Therefore, these tumors were both diagnosed to be GISTs. Mitotic figures were rare in both GISTs. Both GISTs were classified as low-risk, according to the NIH risk classification of GIST. The patient had no family history of GIST and had not experienced NF1. No molecular analysis of mutations in KIT and PDGFR was performed.

The patient had an uneventful recovery and was discharged from the hospital on the 15th day after the operation and followed up in the outpatient clinic. He has survived without recurrence for approximately 12 years since complete resection.

\section{Discussion}

GISTs are commonly regarded as solitary tumors $[3,11]$. The occurrence of multiple GISTs is an extraordinarily rare event restricted to familial GISTs [4], pediatric forms [5], or district syndromes such as NF1 [6] or Carney's syndrome [7]. The presentation of multiple synchronous lesions is commonly viewed as the result of the metastatic spreading of a single primary GIST. The tumors of metastatic GIST are generally located on the peritoneum, but not in the other portions of the gastrointestinal tract [9]. Moreover, the patterns of immunohistochemical and molecular analysis in metastatic GIST are consistent with paired tumors [9]. On the other hand, some reports indicate that the patterns of immunohistochemical and molecular analysis in multiple sporadic GISTs are often different [8-10, 12]. The immunohistochemical analysis in the present case revealed different patterns in the gastric and jejunal GISTs, though no molecular analysis was performed. The patient had no family history of GIST and had not had NF1. Therefore, this case was diagnosed as synchronous sporadic GISTs in the stomach and jejunum.

Familial GISTs patients have a germline mutation in the KIT gene and diffuse hyperplasia of ICC with direct continuity between the GIST mass and the adjacent intestinal wall [8]. Multiple GISTs in NF1 patients are caused by a mutation of the NF1 gene and have focal or mild hyperplasia of ICC [8]. On the other hand, no hyperplasia of ICC is noted in patients with multiple sporadic GISTs [8]. Moreover, the normal control mucosa of multiple sporadic GISTs retains the wild-type KIT gene [8]. The present case had no hyperplasia of ICC in either lesions. This finding supports the finding that the present case was synchronous sporadic GISTs in the stomach and jejunum. The occurrence of the multiple sporadic GISTs was thought to be an accidental event.

Complete gross resection of GISTs with negative margins is the standard primary treatment [10-13]. The Japanese clinical practice guidelines for GIST recommend resection if the submucosal tumor is larger than $2 \mathrm{~cm}$ with clinically malignant signs, whereas observation may be chosen for a tumor smaller than $2 \mathrm{~cm}$ without symptoms or clinically malignant signs [14]. Nevertheless, tumors diagnosed as GISTs should be resected regardless of size because of their malignant potential [14]. Recently, the laparoscopic approach is considered effective and technically feasible when performed by skilled surgeons [10-13, 15]. Laparoscopic wedge resection enables most small $(<5 \mathrm{~cm})$ tumors to be removed with clear margins [15]. However, the laparoscopic approach was not performed in the present case because he was treated 12 years ago. 
Nakayama et al.: Synchronous Sporadic Gastrointestinal Stromal Tumors in the Stomach and Jejunum: Report of a Case

In conclusion, this report presents the surgical case of a patient with synchronous sporadic gastric and jejunal GISTs. Cases of multiple sporadic GISTs are extremely rare.

\section{Disclosure Statement}

The authors have no conflicts of interest to declare.

\section{References}

1 Hirota S, Isozaki K, Moriyama Y, et al: Gain-of-function mutations of c-kit in human gastrointestinal stromal tumors. Science 1998;279:577-580.

-2 Kindblom LG, Remotti HE, Aldenborg F, Meis-Kindblom JM: Gastrointestinal pacemaker cell tumor (GIPACT): gastrointestinal stromal tumors show phenotypic characteristics of the interstitial cells of Cajal. Am J Pathol 1998;152:1259-1269.

-3 Miettinen M, Lasota J: Gastrointestinal stromal tumors - definition, clinical, histological, immunohistochemical, and molecular genetic features and differential diagnosis. Virchows Arch 2001;438:1-12.

4 Hartmann K, Wardelmann E, Ma T, et al: Novel germline mutation of KIT associated with familial gastrointestinal stromal tumors and mastocytosis. Gastroenterology 2005;129:1042-1046.

5 Prakash S, Sarran L, Socci N, et al: Gastrointestinal stromal tumors in children and young adults: a clinicopathologic, molecular, and genomic study of 15 cases and review of the literature. J Pediatr Hematol Oncol 2005;27:179-187.

6 Maertens O, Prenen H, Debiec-Rychter M, et al: Molecular pathogenesis of multiple gastrointestinal stromal tumors in NF1 patients. Hum Mol Genet 2006;15:1015-1023.

7 Carney JA: Gastric stromal sarcoma, pulmonary chondroma, and extra-adrenal paraganglioma (Carney triad): natural history, adrenocortical component, and possible familial occurrence. Mayo Clin Proc 1999;74:543-552.

8 Kang DY, Park CK, Choi JS, et al: Multiple gastrointestinal stromal tumors: clinicopathologic and genetic analysis of 12 patients. Am J Surg Pathol 2007;31:224-232.

-9 Gasparotto D, Rossi S, Bearzi I, et al: Multiple primary sporadic gastrointestinal stromal tumors in the adult: an underestimated entity. Clin Cancer Res 2008;14:5715-5721.

10 Dell'Avanzato R, Caeboni F, Palmieri MB, et al: Laparoscopic resection of sporadic synchronous gastric and jejunal gastrointestinal stromal tumors: report of a case. Surg Today 2009;39:335-339.

11 DeMatteo RF, Lewis JL, Leung D, Muden SS, Woodruff JM, Brennan MF: Two hundred gastrointestinal stromal tumors: recurrence patterns and prognostic factors for survival. Ann Surg 2000;231:51-58.

12 Fujimoto A, Kobayashi T, Uchida S, et al: Laparoscopic total gastrectomy for multiple sporadic gastrointestinal stromal tumors: report of a case. Surg Today 2012;42:84-88.

13 Perez EA, Livingstone AS, Franceschi D, et al: Current incidence and outcomes of gastrointestinal mesenchymal tumors including gastrointestinal tumors. J Am Coll Surg 2006;202:623-629.

14 Nishida T, Hirota S, Yanagisawa A, et al: Clinical practice guidelines for gastrointestinal stromal tumor (GIST) in Japan: English version. Int J Clin Oncol 2008;13:416-430.

15 Bucher P, Egger JF, Gervas P, et al: An audit of surgical management of gastrointestinal stromal tumours (GIST). Eur J Surg Oncol 2006;32:310-314. 


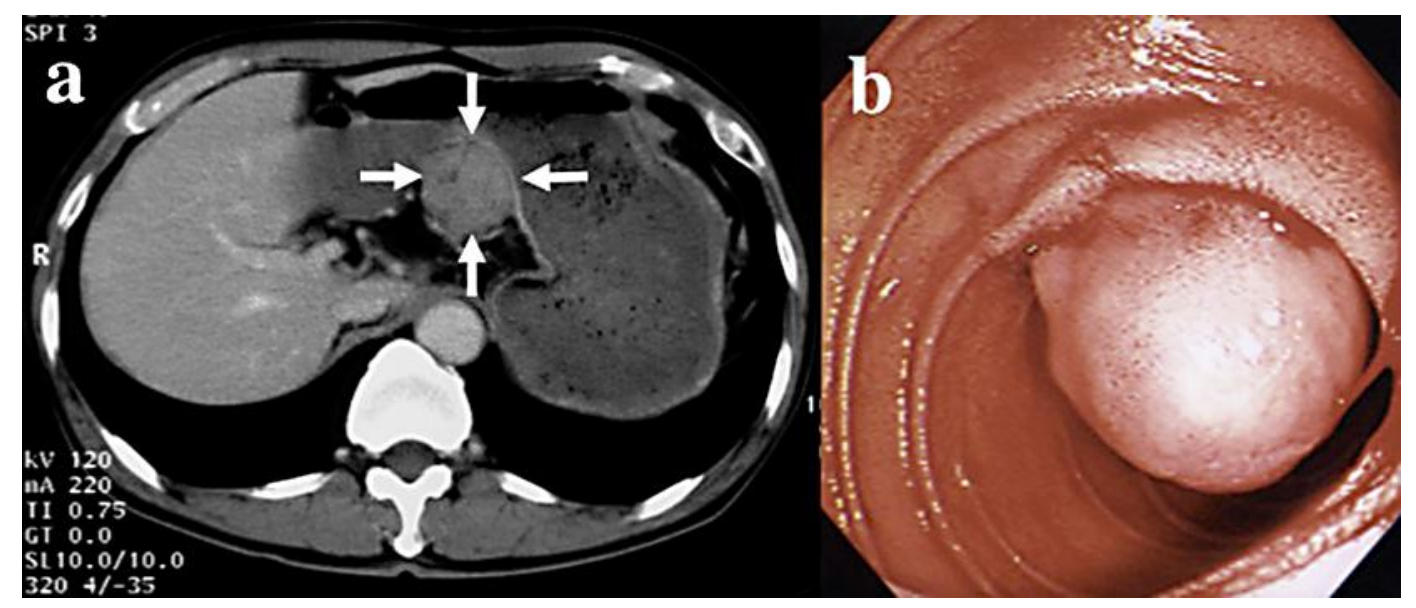

Fig. 1. a Computed tomography of the abdomen demonstrated an enhanced extramural tumor of the stomach that was $4 \mathrm{~cm}$ in diameter (arrows). b Endoscopic examination revealed a jejunal submucosal tumor.
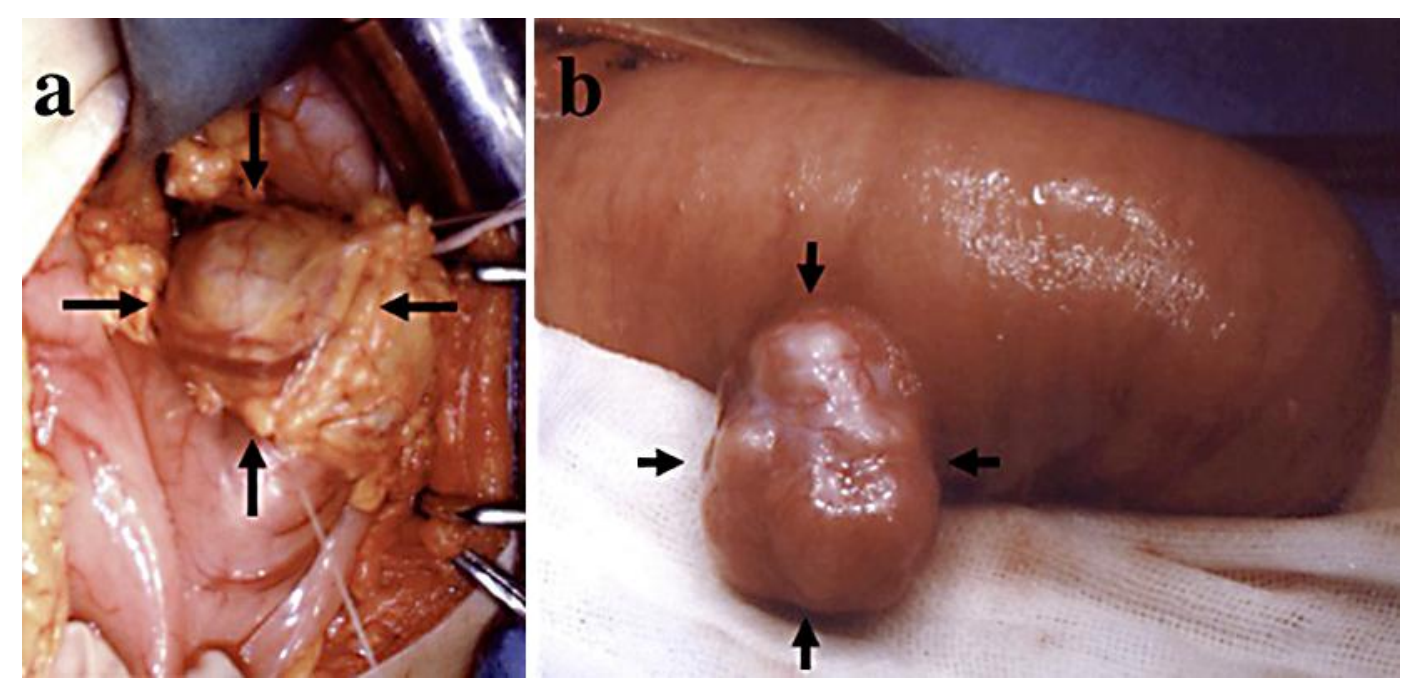

Fig. 2. a A nut-sized extramural tumor was identified at the lesser curvature of the middle stomach (arrows). b A thumb's head-sized tumor was also identified at the jejunum about $15 \mathrm{~cm}$ from the anal side of the Treitz ligament (arrows). 


\section{Case Reports in \\ Gastroenterology}

\begin{tabular}{l|l}
\hline Case Rep Gastroenterol 2013;7:69-74 \\
\hline DOI: $\underline{10.1159 / 000348754}$ & $\begin{array}{l}\text { ○ 2013 S. Karger AG, Basel } \\
\text { www.karger.com/crg }\end{array}$ \\
\hline
\end{tabular}

Nakayama et al.: Synchronous Sporadic Gastrointestinal Stromal Tumors in the Stomach and Jejunum: Report of a Case

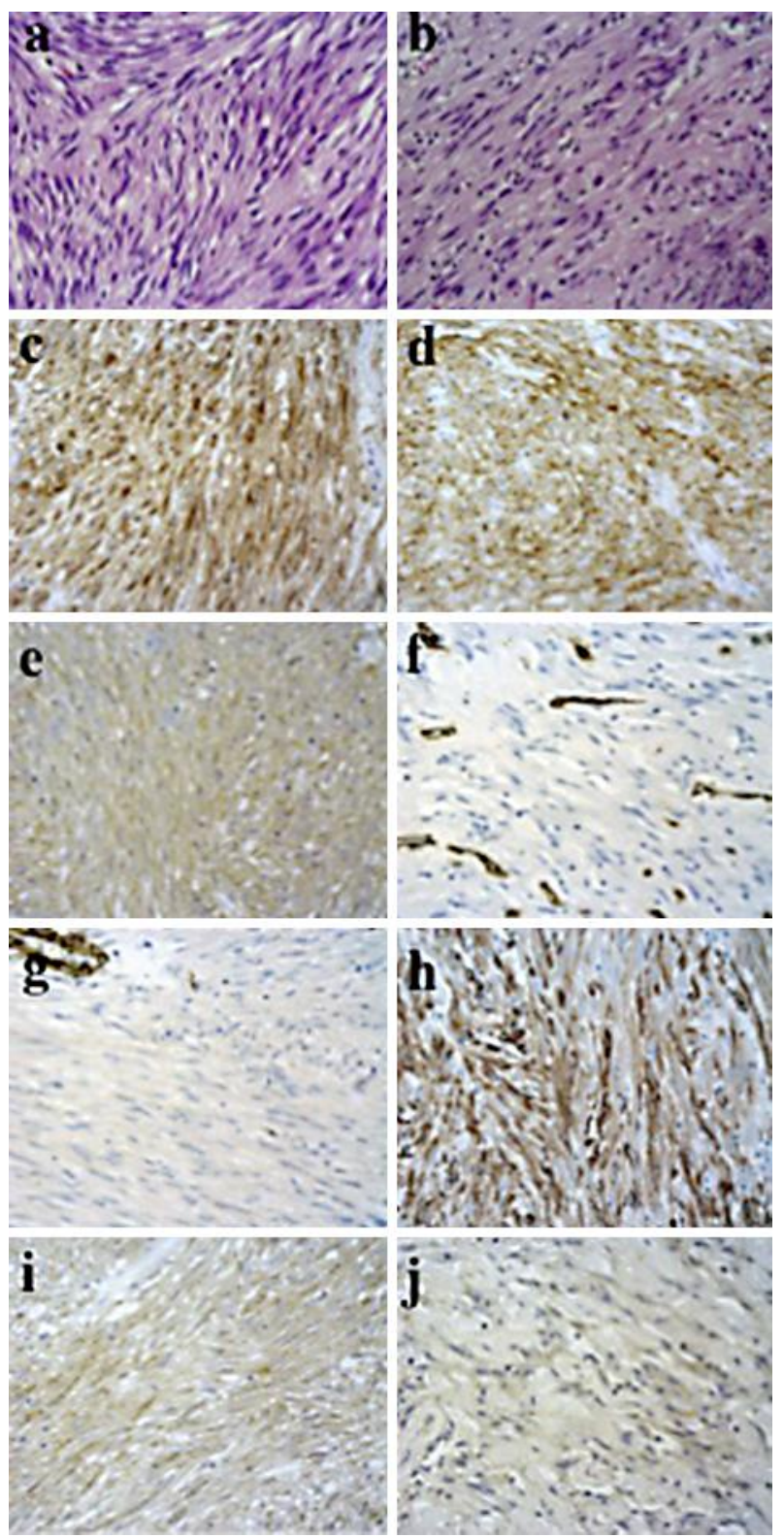

Fig. 3. Histopathological examination with hematoxylin and eosin staining of the gastric GIST $(a, \times 400)$ and the jejunal GIST $(\mathbf{b}, \times 400)$ and immunohistochemical staining patterns of the gastric $(\mathbf{c}, \mathbf{e}, \mathbf{g}, \mathbf{i}, \times 400)$ and jejunal ( $\mathbf{d}, \mathbf{f}, \mathbf{h}, \mathbf{j}, \times 400)$ GISTs. The gastric GIST was positive for $\mathbf{c}-k i t(\mathbf{c})$, CD34 (e) and NSE (i), but negative for SMA (g). On the other hand, the jejunal GIST was positive of c-kit (d), SMA (h) and NSE (j), but negative for CD34 (f). 